\title{
Respiratory cancer in a cohort of nickel sinter plant workers
}

\author{
A CHOVIL, R B SUTHERLAND, AND MABEL HALLIDAY \\ From the Medical Branch, Workmen's Compensation Board, Toronto, and the Department of Preventive \\ Medicine and Biostatistics, and the Occupational Health Unit, Faculty of Medicine, University of Toronto, \\ Toronto, Ontario, Canada
}

\begin{abstract}
A study was undertaken of a cohort of nickel refinery workers from a sinter plant that operated from 1948 to 1962 . A complete follow-up of the 495 workers has been carried out by searching death records and other measures. Incident cases known to the Workmen's Compensation Board of Ontario have been included. Fifty-four cases of lung cancer and eight of sinus cancer (including two in men who subsequently developed primary lung cancer) were located. The risk of lung and sinus cancer was much higher in the earlier days of operation of the plant, with an incidence rate of over $40 \%$ for those employed in the first year of operation. The dose-response relationship has been examined by regressions of standardised mortality ratios (SMR) and standardised incidence ratios (SIR). The SIR suggests that the risk doubled at levels of exposure of 12 months (six months in the earlier years).
\end{abstract}

An excess of lung and sinus cancer associated with the refining of nickel is reported as being first noted ${ }^{1}$ by the chief inspector of factories at the Clydach refinery in Wales before the second world war. The epidemiology of the British experience has been reviewed by Morgan ${ }^{2}$ and Doll, ${ }^{34}$ who suggested that the hazard had been eliminated by 1925 or 1930 -possibly because of process changes or possibly subsequent to the use of protective equipment. The exact carcinogen was never identified. Nickel carbonyl was suspected as was arsenic, which was a contaminant of the sulphuric acid used in the early days, but the evidence does not seem to have been convincing.

International Nickel Company (Inco) opened a Canadian refinery at Port Colborne in Ontario in 1918 to produce nickel and nickel oxide from sulphide matte. Oxidation was initially accomplished by roasting and calcining and later by sintering with coke on travelling grate furnaces. The Port Colborne sinter plant was phased down during the period 1949-58. A new sinter plant went into operation at Copper Cliff near Sudbury in 1948 which operated until February 1963, when it was superseded by the fluid bed roasting process. The sintering process at both plants for producing oxides differed fundamentally from the similar process used

Received 14 October 1980

Accepted 23 January 1981 by Inco to produce a coarse agglomerate of sulphide particles suitable for blast furnace smelting at Coniston. This latter form of sintering was also practised by the Falconbridge Nickel Company near Sudbury until recently, without any apparent health hazard. ${ }^{5}$

Epidemiological studies were carried out by one of us (RBS) for the provincial Government of Ontario on the work force at Port Colborne in 1959 (R B Sutherland, unpublished information; subsequently updated by Inco $^{6}$ ) and at the Copper Cliff sinter plant in 1969 (R B Sutherland, unpublished information). Both studies showed an increased incidence of lung and sinus cancer in men employed in the sinter plant, or in certain dusty furnace operations at Port Colborne. Although neither study was published, Mastromatteo ${ }^{7}$ drew on some of the data in his review of the occupational health aspects of nickel. The Ontario Ministry of Health monitored all deaths in Inco workers subsequent to these studies until 1978, but no excess cancer cases were noted in any other work areas. ${ }^{8}$

Reports from Norway, where the partially refined ores from the Falconbridge mines near Sudbury are treated, have also indicated an excess of lung, sinus, and possibly also laryngeal cancer. ${ }^{9}$

The Copper Cliff operation, which has been described as being extremely dusty, entailed burning a mixture of impure nickel sulphide with coke and a large recycle of partially oxidised "fines" on a 
travelling grate. Ignition, under a combustion hood, was fuelled by oil until 1959 and subsequently by natural gas. The dust produced was a mixture of nickel sulphides and oxides with small amounts of other metals and some carbon. Only limited quantitative and qualitative analyses are available. In addition, considerable sulphur dioxide was evolved in the process. Anecdotal reports from former workers, some of whom used very simple masks at times, indicate that there was considerable variation in the dust intensity in various areas of the plant. Smoking was permitted in the plant, and many of the workers rolled their own cigarettes despite the dusty conditions.

Occupationally caused malignant disease has been recognised under the Workmen's Compensation Act in Ontario since 1947. The present study was undertaken to provide data for review of the criteria for allowance of claims.

\section{Methods and materials}

Records of the original Copper Cliff cohort were available, but unfortunately those for Port Colborne were not.

Data on allowed Workmen's Compensation Board of Ontario (WCBO) claims were on record for both the Port Colborne and the Copper Cliff refineries (table 1). The cases from Copper Cliff include several workers who were not identified when the original cohort was defined but who were subsequently shown to have had some sinter plant exposure. Scattergrams of these data failed to show any relation between latency, defined as the period from first exposure to diagnosis, and the duration of exposure for either type of cancer at either plant.

The original cohort studied at Copper Cliff had consisted of 522 workers with five or more years of total service with the company, including some sinter plant service. It was not a complete roll of all the sinter plant workers but a somewhat stratified random selection that included all durations of exposure. We have undertaken a follow-up of this group to determine both incidence and mortality for lung and sinus cancer for the 16-year period 1963-78, excluding 10 workers who had died before 1963 (including one lung cancer) and 17 workers who were known to have left the country. This left a residual cohort of the study consisting of $\mathbf{4 9 5}$ workers, who had all been employed at the Copper Cliff plant at some time between 1948 and 1962 and who were alive in 1963. A search of death records for the whole of Canada up to the end of 1977 and for Ontario for 1978 was carried out to identify deaths among workers who could not be confirmed from various sources as living. The certified cause of death was determined for all except one of the known fatalities (this man had reportedly died of a myocardial infarct in New York State). In addition, incident cases of lung cancer were identified by WCBO records.

Exposure was recorded in terms of duration of employment in the plant, after allowing for absences due to sickness and strikes. So far as is known, none of these workers had been employed in any known area of carcinogenic hazard before or subsequently with Inco. None had any known exposure to nickel carbonyl. One sinter plant worker who developed lung cancer is known to have had significant radiation exposure in the uranium mines at Elliot Lake (which is geographically proximate) subsequent to his nickel refining exposure.

Observation had suggested that the risk diminished sharply after 1951, and there was some evidence that the actual dust levels might have dropped by half. ${ }^{10}$ A review of the data discussed under tables 4 and 5 below confirmed a definite reduction of risk after 1951 ; thus it was thought that it would be appropriate to weight exposures for men employed during the period 1948-51 by multiplying these exposures by a factor of two for purposes of the dose-response analysis.

For the analysis, the cohort was stratified by durations of exposure into seven subgroups. Unequal intervals of exposure were used to define the groups to obtain relatively equal group sizes, and

Table 1 Claims allowed by WCBO for lung and sinus cancer associated with nickel refining-up to December 1979

\begin{tabular}{lll}
\hline Type of cancer & Port Colborne refining & Copper Cliff refining \\
\hline Lung & 63 & 77 \\
(ICD 162) & Latency range 17-55 yr & Latency range 9-30 yr \\
Nasal sinus & (Mean 33.4, SD 7.9) & (Mean 22.5, SD 4.9) \\
(ICD 160) & 36 & 13 \\
& Latency range 19-46 yr & Latency range 12-28 yr \\
\hline
\end{tabular}

Because exposures at the Port Colborne refinery extended from 1921 to 1958 (including a sinter plant from 1926 onwards) and at the Copper Cliff sinter plant from 1948 to 1963, mean values for latencies are not comparable. The figures refer to "WCBO allowed claims" only and not the total number of cases that may have occurred. At Copper Cliff the figures include cases of workers who were found to have had sinter plant experience subsequent to the definition of the cohort, which forms the main basis for this study. 
Table 2 Results of follow-up of cohort for sinter plant workers from January 1963 to December 1978

\begin{tabular}{lrrr}
\hline & Survivors & Deceased & Total \\
\hline Lung cancer & 17 & 37 & 54 \\
Sinus cancer & 3 & 3 & 6 \\
Other & 266 & 45 & 311 \\
Untraced & 124 & & 124 \\
Total & 410 & 85 & 495 \\
\hline
\end{tabular}

Untraced members are presumed to be survivors, as deaths could not be located on search of death records.

Table 3 Causes of death (workers in cohort up to 31 December 1978)

\begin{tabular}{llll}
\hline & $\begin{array}{l}\text { Total } \\
\text { observed } \\
\text { deaths }\end{array}$ & $\begin{array}{l}\text { Total } \\
\text { expected } \\
\text { deaths }\end{array}$ & SMR \\
\hline All causes & 85 & 59.65 & 1.42 \\
All causes minus lung & 48 & 55.39 & 0.87 \\
cancer & 45 & 13.13 & 3.42 \\
All cancer & 8 & 8.87 & 0.90 \\
All cancer minus lung & 37 & 4.26 & 8.69 \\
cancer & 27 & 29.04 & 0.93 \\
Lung cancer & All circulatory disease & & \\
\hline
\end{tabular}

(Expected deaths were calculated by applying appropriate average rates for province of Ontario for periods 1963-8, 1969-73, and 1974-8, by five-year age groups, adjusting populations for second and third periods by deducting expected deaths from all causes.)

thus avoid the need for complex statistical weighting procedures. Expected deaths for each subcohort (and for the subcohorts defined in table 5) were calculated on the basis of hypothetical controls of similar age distribution drawn from the male population of Ontario. Average age-specific mortality rates for lung cancer and for all causes for three-time periods (1963-8, 1969-73, and 1974-8) were applied, reducing the numbers in each subcohort for the second two periods by the number of expected deaths from all causes in the preceding period.*

Estimates of the expected numbers of cases (incidence) were obtained by multiplying the expected number of deaths by a factor of $1 \cdot 5$. Review of the data comparing incidence with mortality from lung cancer for several provinces in Canada and for a number of countries suggested that some factor over 1.2 would likely be appropriate. The figure of 1.5 was finally selected as being supported by the internal evidence from the study for the ratio of survivors to total cases.

These data were then used to develop standardised mortality ratios (SMR) and standardised incidence ratios (SIR) for each subgroup.

*This simplified method of calculating expected deaths, which tends to inflate the numbers slightly, was used rather than a full life table method. We considered that the slight error was acceptable since no statistical tests were intended.
Results

The results of the follow-up until the end of 1978 are shown in tables 2 and 3. The 37 fatal cases of lung cancer had all been certified as dying from primary lung cancer and the accuracy of diagnosis confirmed either by pathology reports or by review of the clinical records to establish a "best clinical diagnosis" in all except three cases. In these three cases there was peripheral evidence on the death certificates (indications of necropsy or surgical operation) that tended to confirm the accuracy of the diagnosis. In the incident cases the diagnosis had been established on the basis of pathology reports showing invasive lung or sinus cancer. Many of these workers had been followed with a sputum cytology programme. ${ }^{8}$ Although several had had reports of abnormal sputum over periods of several years before an actual primary lung cancer was located, a positive sputum was not considered evidence of cancer, and the dating of incidence is to the pathological confirmation of invasive cancer. Two of the workers who died from primary lung cancer had also suffered from primary sinus cancer. No known cases of laryngeal cancer have occurred in this cohort.

Figure 1 shows the chronological development of cases. The single case of lung cancer diagnosed in 1962 has been considered, for the purposes of this study, to have been incident in 1963. Four cases that have developed after the end of the study period are included.

Period of employment-Tables 4 and 5 show the breakdown by year of first employment at the sinter plant for workers and cases. There is an obvious

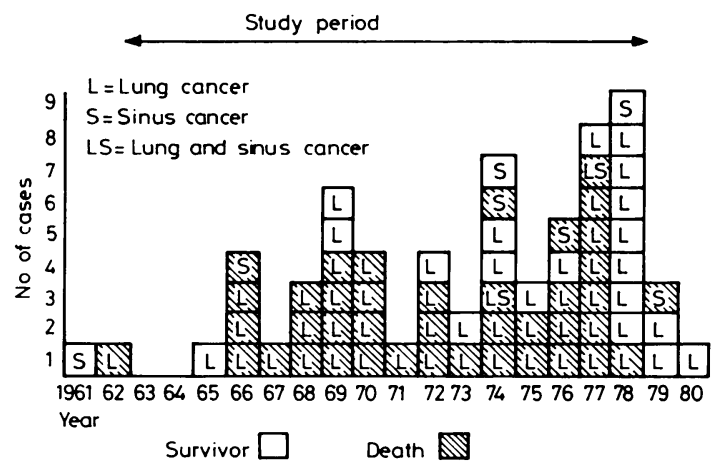

Fig 1 Chronological occurrence of cases of respiratory cancer in cohort of sinter plant workers at Copper Cliff refinery. (Two workers developed both primary lung and primary sinus cancers.) Cases known to have developed after end of study period are included, but vital status of cases in study period are for December 1978. 
Table 4 Distribution of cases in cohort by year of first employment

\begin{tabular}{|c|c|c|c|c|c|c|c|c|c|c|c|c|c|c|c|}
\hline & 1948 & 1949 & 1950 & 1951 & 1952 & 1953 & 1954 & 1955 & 1956 & 1957 & 1958 & 1959 & 1960 & 1961 & Total \\
\hline No of workers in & & & & & & & & & & & & & & & \\
\hline cohort & 39 & 83 & 43 & 114 & 55 & 41 & 10 & 37 & 40 & 7 & 2 & 22 & 2 & $\mathbf{0}$ & 495 \\
\hline Cases of sinus cancer & 4 & 2 & 1 & o & $\mathbf{0}$ & 0 & $\mathbf{0}$ & 0 & $\mathbf{0}$ & $\mathbf{0}$ & $\mathbf{0}$ & $\mathbf{0}$ & $\mathbf{0}$ & 0 & $7^{*}$ \\
\hline $\begin{array}{l}\text { Cases of lung cancer } \\
\text { Total respiratory }\end{array}$ & 13 & 21 & 11 & 9 & $\mathbf{0}$ & 1 & $\mathbf{0}$ & 1 & 1 & $\mathbf{0}$ & $\mathbf{0}$ & 0 & 0 & 0 & 57 \\
\hline $\begin{array}{l}\text { cancers } \\
\% \text { workers affected }\end{array}$ & $\begin{array}{l}17 \\
43 \cdot 6\end{array}$ & $\begin{array}{l}23 \\
27 \cdot 7\end{array}$ & $\begin{array}{l}12 \\
27 \cdot 9\end{array}$ & $\begin{array}{l}9 \\
7 \cdot 9\end{array}$ & $\underline{0}$ & $\begin{array}{l}1 \\
2 \cdot 4\end{array}$ & $\underline{0}$ & $\begin{array}{l}1 \\
2 \cdot 7\end{array}$ & $\begin{array}{l}1 \\
2 \cdot 5\end{array}$ & 0 & 0 & $\underline{0}$ & 0 & 0 & $\begin{array}{l}64 \\
12 \cdot 9\end{array}$ \\
\hline
\end{tabular}

This table includes three cases of lung cancer and one of sinus cancer reported subsequent to end of study period up to May 1980

*The two cases of sinus cancer who subsequently developed lung cancer have been included under lung cancer in this table.

Table 5 Relationship of period of first employment to development of primary lung cancer. Table includes all cases reported January 1963 to December 1978

\begin{tabular}{lcl}
\hline & $\begin{array}{l}1948-51 \\
(n=279)\end{array}$ & $\begin{array}{l}1952-62 \\
(n=216)\end{array}$ \\
\hline $\begin{array}{l}\text { Observed deaths (Ca lung) } \\
\text { (up to 1978) }\end{array}$ & 36 & 1 \\
$\begin{array}{l}\text { Expected deaths (Ca lung) } \\
\text { SMR }\end{array}$ & 3.17 & 1.08 \\
Observed cases (Ca lung) & 11.36 & 0.93 \\
Expected cases (Ca lung) & 51 & 3 \\
SIR* & 4.76 & 1.62 \\
& 10.71 & 1.85
\end{tabular}

*SIR = Standardised incidence ratio using a factor of 1.5 to adjust expected deaths to expected cases.

skewing of the distribution of these cases with only three men entering exposure after 1951. Simple observation of this table confirms that the risk of exposure could not be considered to have remained constant over the whole period, as the skewing could not be accounted for by any difference of age structure or of potential maximum latency.

Dose response-Table 6 shows the results for the different exposure subcohorts. SMRs and SIRs were then employed in a regression analysis using the mid-points of the weighted periods of exposure intervals as defined for each subcohort, as shown in fig 2 .

Latency-In some experimental tumour systems there is a clear relation between the dose of a

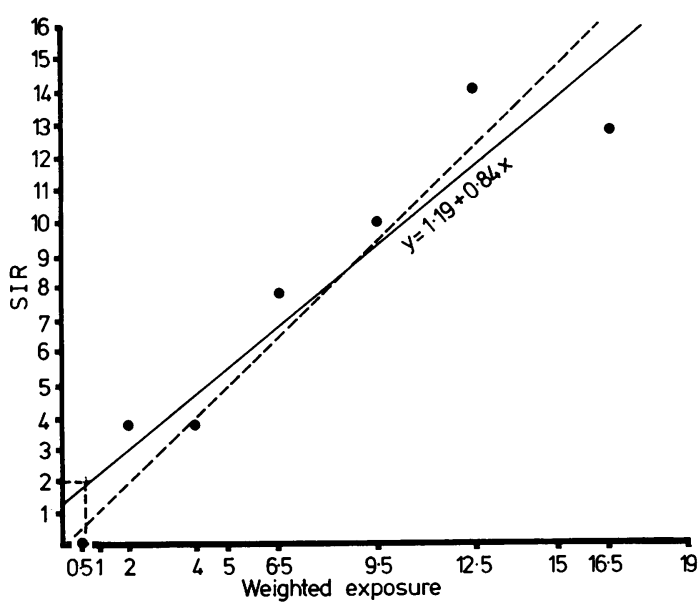

Fig 2 Regression of standardised incidence ratio $(S I R)$ against weighted exposure. ---- represents regression using SMR.

carcinogen and latency. In this series, however, as shown in fig 3, there is no relation between latency and dose (defined as weighted exposure), nor was there any relation between latency and age at first exposure. The relation between latency and year of first employment is shown in fig 4. This figure shows the limited maximum latency possible for these workers.

Survival-Review of the data to May 1980 showed a

Table 6 Cancer incidence in exposure subgroups (January 1963 to December 1978). (Deaths in parentheses)

\begin{tabular}{|c|c|c|c|c|c|c|c|c|}
\hline & \multicolumn{8}{|c|}{ Weighted exposure $(y r)$} \\
\hline & $<1$ & $1-$ & $3-$ & $5-$ & $8-$ & $11-$ & $\geqslant 14$ & Total \\
\hline $\begin{array}{l}\text { Cases of lung cancer } \\
\text { Observed } \\
\text { Expected } \\
\text { Cases of sinus cancer } \\
\text { No of men in subgroups }\end{array}$ & $\begin{array}{l}0 \\
0.71(0.47) \\
0 \\
67\end{array}$ & $\begin{array}{l}2 \\
0.54(0.36) \\
0 \\
78\end{array}$ & $\begin{array}{l}3(3) \\
0.81(0.54) \\
0 \\
72\end{array}$ & $\begin{array}{l}7(4) \\
0.90(0.60) \\
0 \\
77\end{array}$ & $\begin{array}{l}10(6) \\
1.02(0.68) \\
0 \\
70\end{array}$ & $\begin{array}{l}16(13) \\
1 \cdot 14(0 \cdot 76) \\
4(2) \\
66\end{array}$ & $\begin{array}{l}16(11) \\
1 \cdot 26(0 \cdot 84) \\
2(1) \\
65\end{array}$ & $\begin{array}{l}54(37) \\
6 \cdot 38(4 \cdot 25) \\
6(3)^{*} \\
495\end{array}$ \\
\hline
\end{tabular}

*Excluding the two cases of primary sinus cancer who subsequently died of primary lung cancer. 


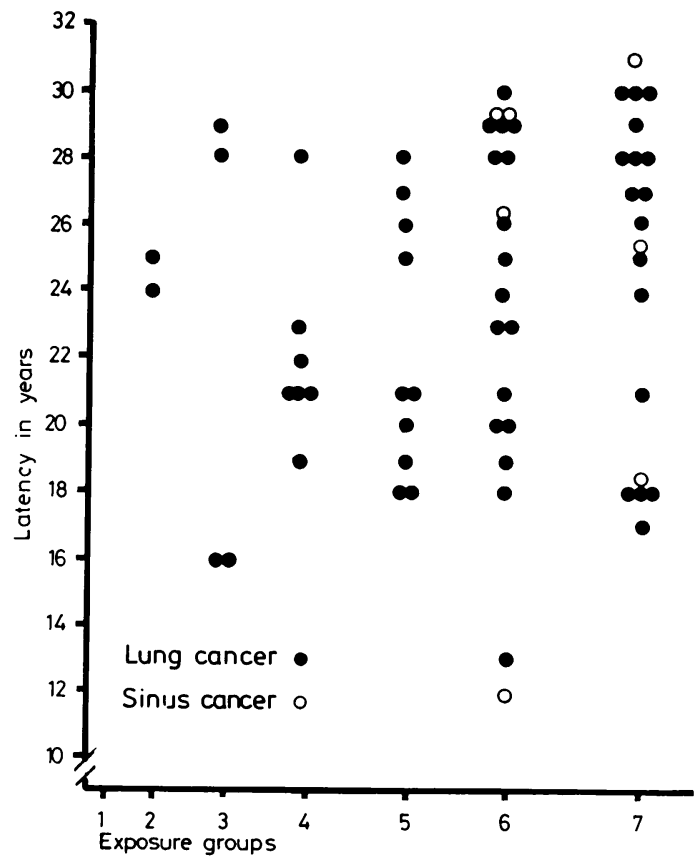

Fig 3 Scattergram of latency by exposure group (including cases up to May 1980). Lung cancer, $\bigcirc$ sinus cancer.

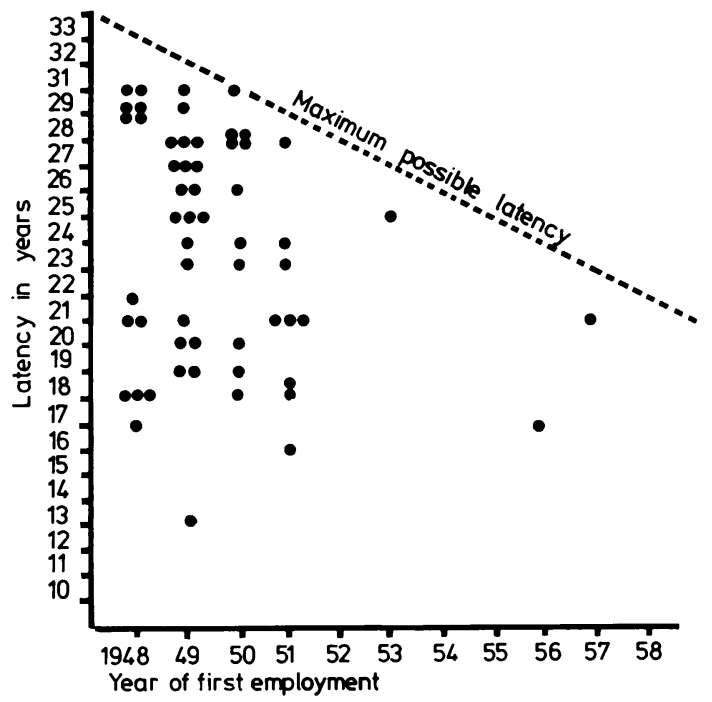

Fig 4 Scattergram of latency by years of first employment (cases of lung cancer developing to May 1980).

five-year survival rate of $29 \%$ for the cases of lung cancer, which is rather better than one would have anticipated from other reports.

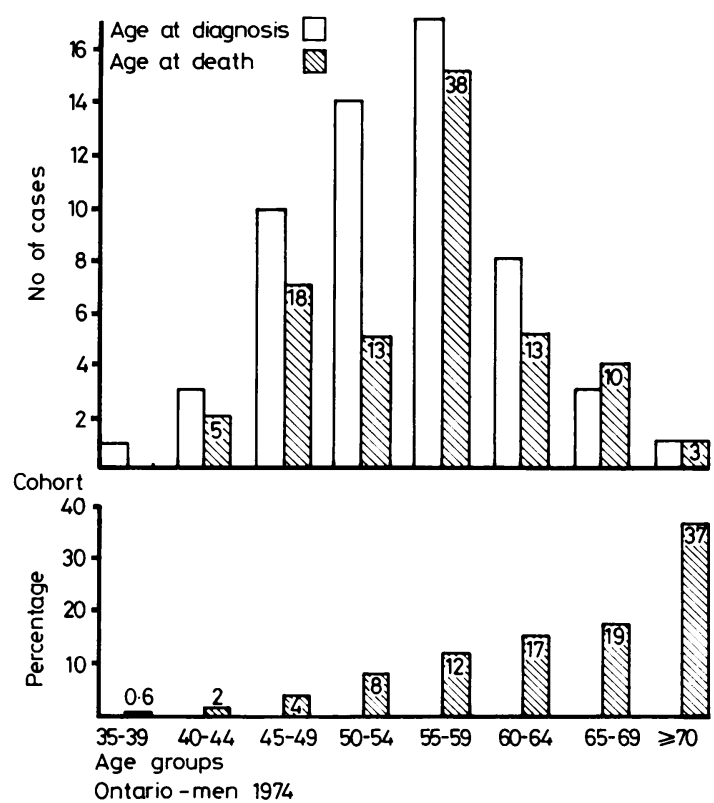

Fig 5 Age distribution of cases of lung cancer and deaths in cohort up to May 1980 compared with distribution of deaths from lung cancer for Ontario men in 1974. (Figures in shaded bars are percentages.)

Age at diagnosis-The distributions of the age at diagnosis of the 57 cases of lung cancer, together with the distributions of age at death ( 39 cases) are shown in fig 5 . The proportionate distribution of deaths from lung cancer by age for the province of Ontario in 1974 is shown in addition. These distributions are not strictly comparable in view of the non-standardised age structure, but it is suggestive that lung cancers in nickel workers are occurring at a younger age than "spontaneous" cancers.

Tissue type-Histological data were available on 43 cases. Thirty-nine $(91 \%)$ were reported as squamous, two $(5 \%)$ as oat-cell, and two $(5 \%)$ as adenocarcinomas. This is appreciably different from a series of lung cancers in uranium miners, reviewed by one of us (ACC), where $55 \%$ were oat-cell, $37 \%$ squamous, and $8 \%$ adenocarcinomas.

\section{Discussion}

Many unanswered questions about nickel carcinogenesis remain. Which compounds are actually carcinogenic in man and how they act is not clear. Several insoluble salts are effective animal carcinogens, ${ }^{1}$ but human cases seem to occur predominantly where the expcsure is to partially or 
completely oxidised material. Nickel ions have been traced to the cellular level, but the exact mechanism of action remains obscure.11 There is an interesting suggestion that nickel ions may block the production of enzymes, including one concerned in the degradation of the carcinogenic breakdown products of benz(a)pyrene; ${ }^{12}$ Sunderman has fully reviewed this subject. ${ }^{13} 14$

The workers in this sinter plant were heavily exposed to a mixture of nickel sulphides (including the subsulphide), nickel oxides, and to sulphur dioxide. The process involved ignition with fuel oil and a mixture with coke so that significant quantities of polynuclear aromatic (PNA) compounds may also have been generated, but there are no reports of any analyses for such substances. Unfortunately, details of smoking histories are not known for most of the cases; however, anecdotal evidence does suggest that over $90 \%$ of these workers smoked cigarettes.

The outstanding feature of this study is the extremely high incidence of respiratory cancer in the cohort, ranging from $12.9 \%$ overall to the high of over $40 \%$ for the subgroup who began employment in 1948, after a maximum potential latency of only 28 years. Possibly as the result of a high level of community awareness, aided by the cytology programme, the five-year survival rate for lung cancer is encouragingly higher than would normally be anticipated. It is obvious from these incidence rates that the suggestion that carcinogens affect only small subgroups of susceptible subjects in a population does not apply. Whatever carcinogen or combination of carcinogens was concerned must have been extremely potent. It is also obvious that while smoking may have played some part as an inducer or promoter, the overwhelming carcinogen was in the occupational environment. Whether this was a nickel compound acting alone or synergistically with other trace elements or PNAs, or both, is a matter for speculation.

The effects of small exposure on the incidence of lung cancer remain somewhat doubtful, although we are able to show a convincing linear dose response. Our regression suggests that the incidence of lung cancer doubles for workers with more than 12 months' exposure (six months before 1951). Confidence limits, however, cannot properly be applied. The relatively broad confidence limits associated with the end of a regression line would be increased by the fact that an arbitrary weighting factor has been used for the exposures. The choice of the factor used to convert expected mortality to expected incidence also has a critical effect on the slope and intercept of the regression.

The reason for the apparent sudden diminution of risk after 1951 remains quite unclear, since other than a gradual diminution in total dust no process changes have been identified.

The nine cases of sinus cancer are too few to permit any conclusions about the dose response. Comparing the proportion of lung cancer to sinus cancer experienced by this cohort with that experienced by the Port Colborne refinery, as shown in table 1 , one would conclude that somewhat different factors must have been operating, as the difference in proportions cannot be accounted for by the differences in maximum latencies possible. This would seem likely to be associated with the fact that the exposure at Copper Cliff was solely in the sinter plant, whereas almost all the workers at Port Colborne had mixed exposures, including furnaces and electrolytic processes.

We thank the following organisations for help: INCO Ltd, Local 6500, United Steelworkers of America, the Ministry of Labour for Ontario, the Ontario Cancer Treatment and Research Foundation, Statistics, Canada, and the Registrars General of Ontario and the other provinces.

\section{References}

${ }^{1}$ IARC Working Group on the Evaluation of the Carcinogenic Risk of Chemicals to Man. Asbestos, cadmium, and nickel. Vol II. Lyons: IARC, 1976:75-104.

2 Morgan JG. Some observations on the incidence of respiratory cancer in nickel workers. $\mathrm{Br} J$ Ind $\mathrm{Med}$ 1958;15:224-34.

${ }^{3}$ Doll $\mathbf{R}$. Cancer of the lung and nose in nickel workers. Br J Ind Med 1958;15:217-23.

${ }^{4}$ Doll R, Mathews JD, Morgan LG. Cancers of the lung and nasal sinuses in nickel workers: a reassessment of the period of risk. Br J Ind Med 1977;34:102-5.

${ }^{5}$ Nickel and its inorganic compounds (including nickel carbonyl). Toronto: International Nickel (US) Inc, 1976:4-5. (A supplementary submission to the National Institute for Occupational Safety and Health.)

- Nickel and its inorganic compounds (including nickel carbonyl). Toronto: International Nickel (US) Inc, $1976: 22$. (A supplementary submission to the National Institute for Occupational Safety and Health.)

7 Mastromatteo E. Nickel: a review of its occupational health aspects. JOM 1967;9:127-36.

${ }^{8}$ McEwan JC. Cytological monitoring of nickel sinter plant workers. Ann NY Acad Sci 1976;271:365-9.

- Pedersen E, Hogetveit AC, Anderson A. Cancer of respiratory organs among workers at a nickel refinery in Norway. Int J Cancer 1973;12:32-41.

${ }^{10}$ Nickel and its organic compounds (including nickel carbonyl). Toronto: International Nickel (US) Inc. 1976: 90-8. (A supplementary submission to the National Institute for Occupational Safety and Health.)

11 Committee on Medical and Biologic Effects of Environmental Pollution. Nickel. Washington: National 
Research Council, National Academy of Sciences, 1975:174-9.

${ }^{12}$ Blomberg M, Hallste E, Henrikson-Enflo A, et al. Nickel. Stockholm: Institute of Physics, University of Stockholm: March, 1977.

\section{Corrections}

Relation between progressive massive fibrosis, emphysema, and pulmonary dysfunction in coalworkers' pneumoconiosis (May 1981)

We regret that figures 1 and 2 in this article were incorrect. They should have been:

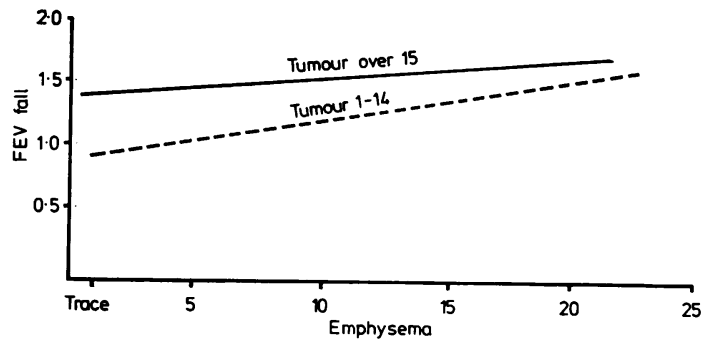

Fig 1 Fall in FEV and emphysema for large and small $P M F$.

Health of workmen in the cromate producing industry in Britain (May 1981)

The date that the production of chromates started at the Rutherglen location should have read 1830 (p 118).
${ }^{13}$ Sunderman FW. A review of the carcinogenesis of nickel, chromium, arsenic, compounds in man and animals. Prev Med 1976;5:279-94.

${ }^{14}$ Sunderman FW. A review of the metabolism and toxicology of nickel. Ann Clin Lab Sci 1977;7:377-98.

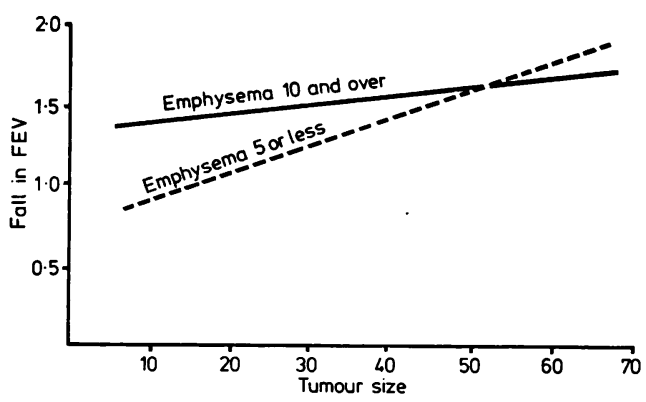

Fig 2 FEV fall and tumour size in slight and extensive emphysema. 